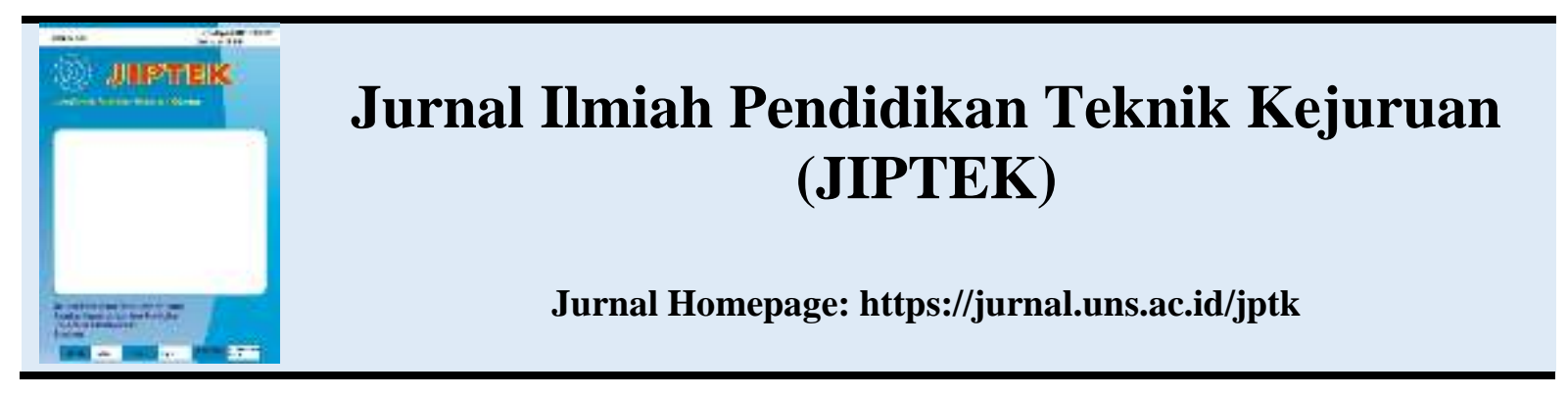

\title{
PENGEMBANGAN SISTEM INFORMASI AKADEMIK BERBASIS WEB SEBAGAI SISTEM PENGOLAHAN NILAI SISWA DI SMK NEGERI 1 KUDUS
}

\author{
${ }^{1}$ Farid Suryandani, ${ }^{1}$ Basori, ${ }^{1}$ Dwi Maryono \\ Program Studi Pendidikan Teknik Informatika dan Komputer, Universitas Sebelas Maret, \\ E-mail: faridsuryandani@gmail.com
}

\begin{abstract}
This research aims to produce an information system of grade processing to allow the teacher in manage a report card of student grade. This information system is intended for use in vocational high school. This information system is web based, so it can be accessed by teacher to manage grades and students can see the result of their study. Method of this research is research and development $(R \& D)$ that implemented in SMK Negeri 1 Kudus. The data collection techniques are interview, quesioner and documentation. The Development of Academic Information System as a Web Based on Processing System of Student Grade in SMK Negeri 1 Kudus carried out with five stages : (1) Communication is discussions between researchers with the school about developing the system, (2) Planning is the planning needs of the functional, software and hardware requirements of the system are developed, (3) Modeling is the stage of system design that focuses on data processing. This phrase begins with the making of Usecase Diagram, Flowchart, DFD (Data Flow Diagram), ERD (Entity Relationship Diagram), Design of data base tables and their relationships and manufacturing design of interface system, (4) Construction is the stage where the design has been created, implemeted into the code (programme), (5) Deployment is the testing phrase to SMK to get feedback on the feasibility and development of a system which further. The final value of this research is 93,1\% from expert system, $85,3 \%$ from the teacher and administration staff and $82.4 \%$ from the students, so it means that the system is highly feasible to be used.
\end{abstract}

Keywords : Academic Information System, web based, management of students grade

\section{Abstrak}

Penelitian ini bertujuan untuk menghasilkan sebuah sistem informasi pengelolaan nilai untuk memudahkan guru dalam mengelola nilai rapor siswa. Sistem informasi ini ditujukan untuk digunakan di Sekolah Menengah Kejuruan (SMK). Sistem informasi ini berbasis web, sehingga dapat diakses oleh guru untuk mengelola nilai dan siswa bisa melihat hasil belajarnya. Metode yang digunakan dalam penelitian ini adalah metode penelitian dan pengembangan (R\&D) yang dilaksanakan di SMK Negeri 1 Kudus. Teknik pengumpulan data yaitu melalui wawancara, kuesioner dan dokumentasi. Pengembangan Sistem Informasi Akademik Berbasis Web Sebagai Sistem Pengolahan Nilai Siswa di SMK Negeri 1 Kudus dilaksanakan dengan lima tahap yaitu : (1) Communication merupakan diskusi antara peneliti dengan pihak sekolah tentang pengembangan sistem. (2) Planning merupakan tahap perancangan kebutuhan fungsional, kebutuhan software dan kebutuhan hardware dari sistem yang dikembangkan. (3). Modeling yaitu tahap perancangan sistem yang berfokus pada pemrosesan data. Tahap ini dimulai dengan pembuatan Usecase Diagram, Flowchart, DFD (Data Flow Diagram), ERD (Entity Relationship Diagram), Desain Tabel Basis Data dan Relasinya dan pembuatan Desain Tampilan Sistem. (4) Construction yaitu tahapan pada rancangan yang telah dibuat, di implementasikan 
ke dalam kode (program). (5) Deployment merupakan tahap pengujian kepada pihak SMK untuk mendapatkan umpan balik tentang kelayakan dan pengembangan sistem yang selanjutnya. Nilai akhir dari penelitian ini adalah $93,1 \%$ dari ahli sistem, $85,3 \%$ dari guru dan staf tata usaha dan $82,4 \%$ dari siswa, sehingga dapat disimpulkan bahwa sistem ini sangat layak untuk digunakan.

Kata kunci : Sistem Informasi Akademik, berbasis web, pengelolaan nilai siswa

\section{Pendahuluan}

Biasanya sekolah dalam melakukan pengelolaan nilai siswa menggunakan cara yang manual, artinya menggunakan buku sebagai rekapan nilai siswa. Jadi ketika nilai itu dibutuhkan dalam pengelolaan rapor atau penyampaian nilai kepada siswa kurang efesien karena masih menggunakan cara yang konvensional. Hal tersebut dirasa kurang baik dari segi penggunaan waktu dan tenaga. Karena alasan tersebut diatas diperlukan penerapan dari kemajuan teknologi agar dapat mengatasi masalah tersebut.

Lembaga pendidikan yang mengoptimalkan perkembangan dan kesiapan peserta didik dalam memasuki dunia industri adalah Sekolah Menengah Kejuruan (SMK). Pada penelitian ini dilaksanakan di SMK Negeri 1 Kudus yang merupakan sekolah menengah kejuruan yang berlokasi di Kecamatan Kota, Kudus, Jawa Tengah. Dalam melakukan pengolahan nilai siswa di SMK Negeri 1 Kudus masih menggunakan aplikasi Excel. Penggunaan aplikasi Excel masih dirasa kurang nyaman untuk guru dalam pengisian nilai dengan data nilai yang begitu banyak. Kekurangan pada penggunaan aplikasi Excel yaitu kurang user friendly, terkadang untuk melakukan rekap nilai semester sebelumnya mengalami kesulitan karena berbeda file serta terkadang data yang ada pada guru dan wali kelas bisa saja berbeda seperti pada nama atau nilai siswa karena penyimpanan data yang berbeda. Oleh karena itu dibutuhkan sebuah solusi yang dapat mengoptimalkan kinerja dalam pengolahan nilai yaitu dengan penggunaan sistem informasi akademik dengan penyimpanan data yang terintegrasi dan terpusat menggunakan basis data.

Kemudian alasan sistem informasi akademik berbasis web adalah kemudahan dalam cara mengaksesnya yaitu dengan cara mengakses lewat browser yang ada pada perangkat komputer atau perangkat telepon. Pada sistem informasi akademik juga dapat mengelola data nilai siswa dan menampilkan hasil nilai siswa yang terbaru serta dapat diakses dimanapun guru dan siswa berada.
Sistem informasi akademik ini memudahkan siswa untuk terus memantau dan mengetahui nilai hasil belajarnya serta memberikan kemudahan bagi guru dalam pengisian nilai, karena dapat dilakukan dimanapun dan kapanpun.

Sistem informasi akademik ini dibangun dan ditujukan untuk melakukan kegiatan akademik yang terstruktur dan terintegrasi menggunakan bahasa pemrograman PHP yang dikolaborasi dengan HTML, MySQL serta Apache. Sehingga dapat dihasilkan mekanisme yang lebih baik dan maksimal dengan menggunakan penyimpanan data yang tersentralisasi yang dapat memudahkan dalam pengelolaan data dengan menggunakan teknologi komputer.

Penelitian ini bertujuan untuk terciptanya Sistem Informasi Akademik Berbasis Web sebagai sistem pengolahan nilai siswa di SMK Negeri 1 Kudus. Selain itu untuk mengetahui kelayakan dari Sistem Informasi Akademik Berbasis Web sebagai sistem pengolahan nilai siswa di SMK Negeri 1 Kudus.

Menurut Fadjar (2002: 5) akademik adalah keadaan orang-orang bisa menyampaikan dan menerima gagasan, pemikiran, ilmu pengetahuan, dan sekaligus dapat mengujinya secara jujur, terbuka, dan leluasa.

Basis data adalah kumpulan terintegrasi dari elemen data yang secara logika saling berhubungan (O'Brien dan Marakas (2010: 173)). Data Base Management System (DBMS ) adalah perangkat lunak basis data yang memungkinkan pengguna untuk membuat, mengakses, dan mengelola basis data (Shelly dan Velmaart, 2011: 152 - 153).

Sistem informasi akademik adalah suatu sistem yang dibuat oleh manusia untuk mengolah data dan informasi yang berkaitan dengan akademik pada suatu organisasi atau instansi pendidikan baik formal maupun informal dari tingkat dasar sampai tingkat perguruan tinggi. Secara singkat sistem informasi akademik adalah aplikasi yang dapat memudahkan dalam pengolahan data dan informasi yang berkaitan dengan hal akademik. 
Penelitian yang dilakukan oleh Wiyono, Gurid B. Wardati Indah U. (2014) menghasilkan bahwa analisis dan perancangan sistem informasi akademik memberikan gambaran pihak Sekolah Menengah Pertama (SMP) Negeri III Tegalombo dalam proses pengolahan data siswa yang lebih praktis, mudah, cepat dan akurat dalam menyajikan informasi.

Kemudian berkaitan dengan sistem informasi akademik berbasis web Bharamagoudar, S.R., Geeta R.B., Totad, S.G. (2013) menghasilkan bahwa sistem informasi dapat memberikan data yang selalu ter-update, meningkatkan efisiensi dalam pengelolaan data, dan mengurangi waktu yang dibutuhkan untuk mengakses data siswa.

\section{Metode Penelitian}

Pada penelitian ini menggunakan model pengembangan waterfall. Menurut Pressman (2010: 46) model pengembangan waterfall merupakan model pengembangan yang sistematis dan berurutan (sekuensial). Waterfall mempunyai tahapan pengembangan yaitu communication, planning, modeling, construction dan deployment.

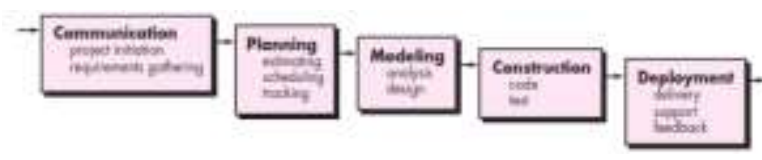

Gambar 1. Model Waterfall

Pada penelitian ini teknik sampling yang digunakan adalah nonprobability sampling. Menurut Sugiono (2010: 66) nonprobability sampling merupakan teknik sampling dengan memberi kesempatan berbeda pada setiap anggota populasi untuk dipilih menjadi sampel. Jenis nonprobability sampling yang dipilih yaitu purposive sampling dan quota sampling.

\section{Purposive Sampling}

Pemilihan sampel berdasarkan penilaian peneliti bahwa sampel tersebut memiliki kaya informasi. Sampel yang dipakai adalah dua dosen Pendidikan Teknik Informatika dan Komputer sebagai ahli sistem serta satu guru dan empat staff tata usaha yang menangani hal yang berkaitan dengan teknologi informasi SMK Negeri 1 Kudus sebagai ahli substansi.

\section{Quota Sampling}

Penentuan sampel dari populasi yang mempunyai ciri-ciri tertentu sampai jumlah (quota) yang dikehendaki. Ukuran sampel yang dipakai adalah sebanyak 30 Orang. Sampel adalah 30 pelajar kelas X Akuntasi 1 SMA Negeri 1 Kudus.

Metode pengumpulan data pada penelitian ini terbagi menjadi beberapa metode yang digunakan untuk mengetahui atau mendapatkan gambaran tentang masalah yang terjadi di sekolah. Metode pengumpulan data yang digunakan pada penelitian ini adalah sebagai berikut :

1. Metode Observasi

Metode Observasi adalah metode pengumpulan data pada objek dengan cara melihat dan memahami. Metode Observasi digunakan untuk menentukan masalah-masalah yang terkait dengan pengelolaan nilai siswa.

2. Metode Dokumentasi

Metode dokumentasi adalah metode pengumpulan data dengan menghimpun dan menganalisis dokumen, baik dokumen tertulis, gambar, maupun elektronik. Metode ini digunakan untuk mendapatkan data tentang masalah-masalah yang terkait dengan pengelolaan data dan informasi akademik sekolah.

3. Metode Literatur dan Kepustakaan

Metode ini merupakan sebuah metode pengumpulan data dengan cara mencari informasi dari berbagai buku terkait dengan penelitian ini. Metode literatur dan kepustakaan ini digunakan untuk mencari referensi dan teori - teori yang berhubungan dengan penelitian ini.

4. Metode Kuesioner

Menurut Sugiyono (2014: 142) kuesioner merupakan teknik pengumpulan data yang dilakukan dengan cara memberi seperangkat pertanyaan atau pertanyaan tulisan kepada responden untuk dijawabnya.

Menurut (Suharsimi, (2010: 268) dalam pembuatannya, kuesioner memiliki prosedur penyusunan yang harus dilakukan yaitu menetapkan tujuan, menetapkan aspek yang akan diungkap, menentukan jenis dan bentuk

kuesioner, menyusun kuesioner dan menentukan skor. Penelitian ini menggunakan kuesioner yang digunakan untuk menilai kelayakan dari Sistem Informasi Akademik Berbasis Web. Metode ini akan berjalan saat tahap deployment. Responden yang dilibatkan untuk dapat memberikan penilaian terhadap sistem ini adalah :

a. Ahli Sistem

Ahli sistem merupakan seorang yang menguasai tentang perancangan sebuah sistem.

b. Ahli Substansi 
Ahli substansi merupakan seorang yang menguasai tentang materi yaitu tentang pengelolaan nilai siswa di sekolah.

c. Siswa

Siswa merupakan responden dari penggunaan sistem pengelolaan nilai siswa yang dikembangkan.

Instrumen penelitian yang digunakan untuk menguji kelayakan dari sistem yang dibuat berdasarkan ISO 9126 dan Romas, A.,M. (2015), kemudian telah dilakukan beberapa modifikasi dan telah divalidasi oleh Bapak Dwi Maryono, S.Si, M.Kom.

Analisis data dilakukan untuk mengolah data dari kuesioner penelitian yang ditujukan pada ahli sistem, ahli substansi dan siswa. Hasil dari analisis digunakan sebagai acuan untuk perbaikan sistem yang dibuat. Langkah yang dilakukan adalah mengubah skor menjadi persentase. Cara menghitung persentase dilakukan dengan membagi jumlah skor yang diperoleh dengan jumlah skor maksimal. Pada perhitungan SUS untuk kuesioner siswa bernilai 0 sampai dengan 4 . Perhitungan pada nomor item 1, 3, 5, 7, 9 bernilai skor dikurangi satu dan pada nomor item 2, 4, 6, 8, 10 bernilai lima dikurangi skor. Cara menghitung persentase dilakukan dengan menggunakan rumus sebagai berikut:

$$
\begin{aligned}
& \text { Persentase }(\%) \\
& =\frac{\text { Jumlah skor yang diperoleh }}{\text { Jumlah skor maksimal }} \times 100 \\
& \quad \text { Sumber: Sugiyono (2014: 93) }
\end{aligned}
$$

Berikut adalah kategori yang didapat dari skor yang telah dikonversi menjadi sebagai berikut:

Tabel 1. Konversi Skor dalam Bentuk Persentase

\begin{tabular}{cc}
\hline Kategori Penilaian & Skor \\
\hline Sangat Layak & $81 \%-100 \%$ \\
\hline Layak & $61 \%-80 \%$ \\
\hline Cukup Layak & $41 \%-60 \%$ \\
\hline Tidak Layak & $21 \%-40 \%$ \\
\hline Sangat Tidak Layak & $0 \%-20 \%$ \\
\hline
\end{tabular}

Sumber: Sugiyono (2014: 93)
Pada tahap communication merupakan tahap awal dari pengembangan sistem yang bermula dari komunikasi tentang pengembangan sistem yang akan dilakukan. Tahap ini menghasilkan berbagai informasi untuk melakukan tahap - tahap selanjutnya. Informasi yang didapat dimaksudkan untuk memahami tujuan - tujuan dari pengembangan sistem yang dilakukan untuk mengatasi masalah yang ada bahwa dalam melakukan pengolahan nilai siswa di SMK Negeri 1 Kudus masih menggunakan aplikasi Excel. Penggunaan aplikasi Excel masih dirasa kurang nyaman untuk guru dalam pengisian nilai dengan data nilai yang begitu banyak.

Kekurangan pada penggunaan aplikasi Excel yaitu kurang user, banyakan data yang harus dikelola pada file excel yang berbeda untuk rapor siswa tiap, terkadang untuk melakukan rekap nilai semester sebelumnya mengalami kesulitan karena berbeda file serta terkadang data yang ada pada guru dan wali kelas bisa saja berbeda seperti pada nama atau nilai siswa. Setelah dilakukan diskusi tentang permasalahan tersebut maka di dapatkan hasil untuk melakukan Pengembangan Sistem Informasi Akademik Berbasis Web Sebagai Sistem Pengolahan Nilai Siswa.

Tahap Planning

Pada tahap planning merupakan tahap pengembangan sistem setelah tahap communication. Planning merupakan tahapan untuk mendefinisikan suatu peta jalan (roadmap) untuk mencapai tujuan dari Pengembangan Sistem Informasi Akademik Berbasis Web Sebagai Sistem Pengolahan Nilai Siswa. Pada tahapan ini menghasilkan analisis tentang kebutuhan sistem seperti kebutuhan fungsional, kebutuhan software dan hardware dari sistem.

Tahap Modeling

Pada tahap modeling merupakan tahap model analisis untuk mendapatkan pemahaman yang lebih baik tentang Sistem Informasi Akademik Berbasis Web Sebagai Sistem Pengolahan Nilai Siswa. Pada tahap ini dilakukan langkah - langkah seperti membuat rancangan usecase, rancangan flowchart, rancangan DFD, rancangan ERD, rancangan tabel basis data dan pembuatan desain tampilan.

\section{Hasil Penelitian Dan Pembahasan}

Tahap Communication 


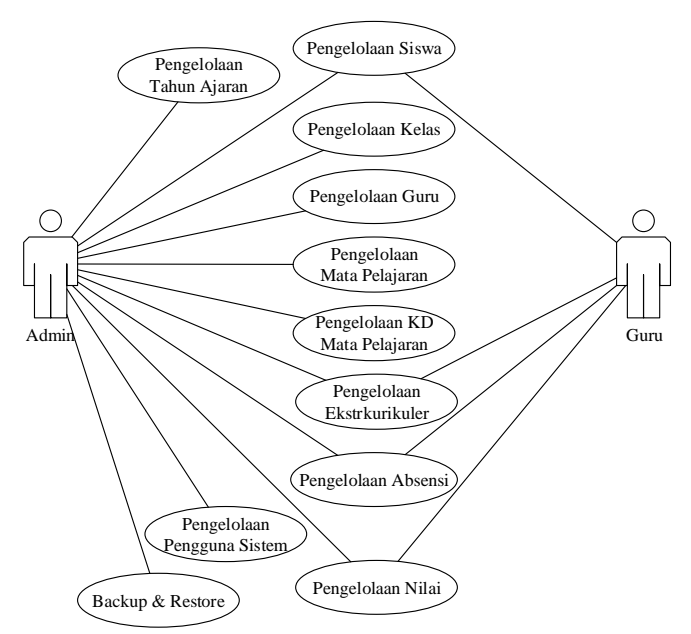

Gambar 2. Usecase Admin dan Guru

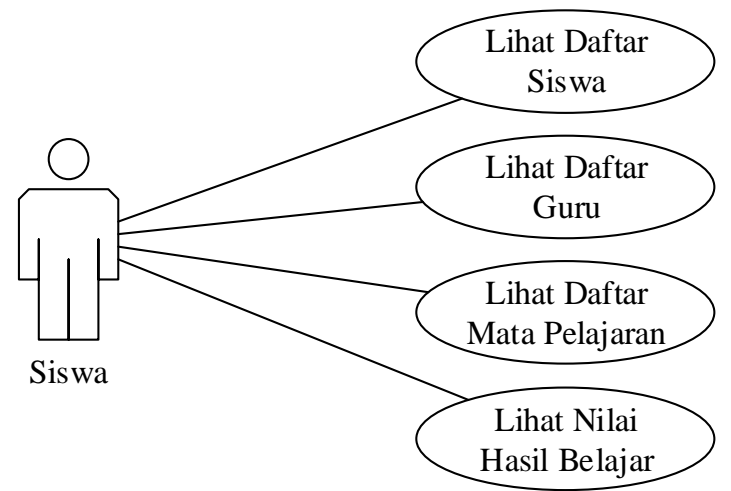

Gambar 3. Usecase Siswa

Seperti pada Gambar 2 dan Gambar 3 adalah rancangan usecase diagram yang digunakan untuk memberikan deskripsi paling sederhana tentang fungsi dasar yang bisa dilakukan sistem.

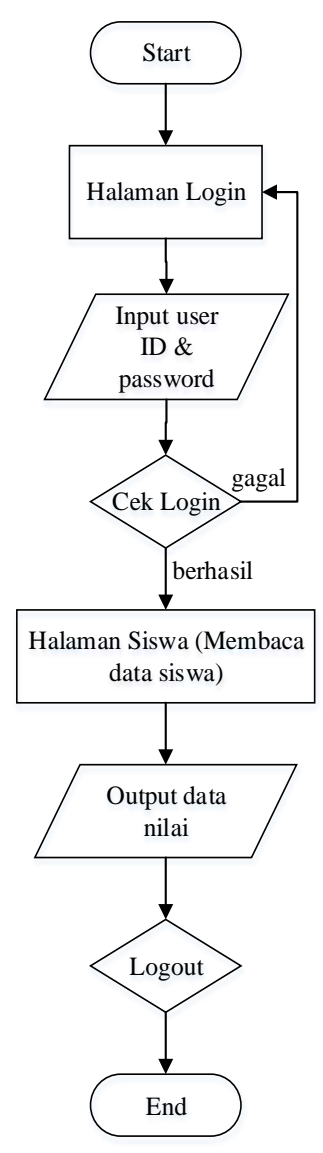

Gambar 4. Flowchart siswa untuk melihat nilai hasil belajar

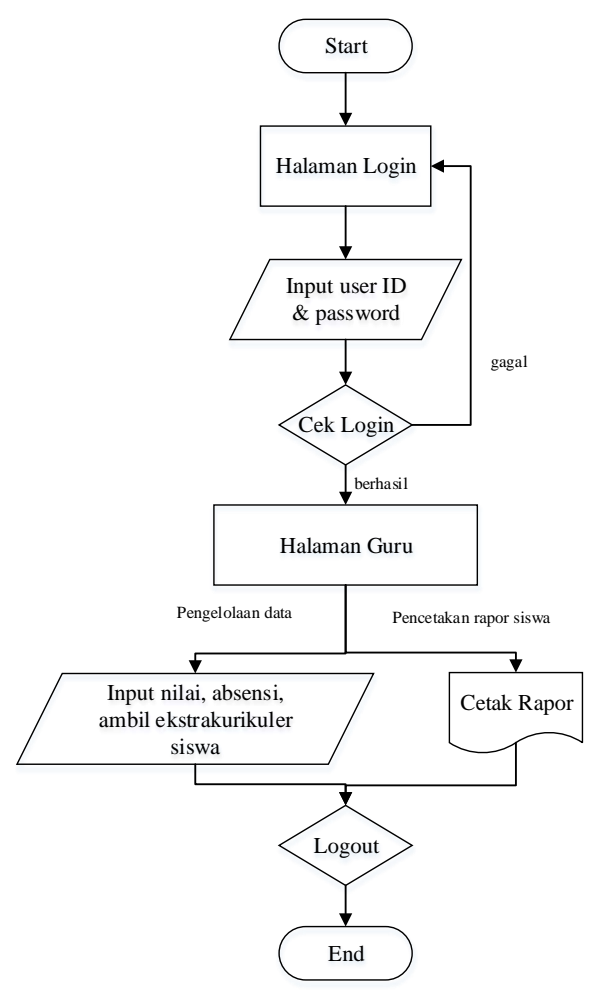

Gambar 5. Flowchart guru melakukan input data rapor dan cetak rapor siswa 


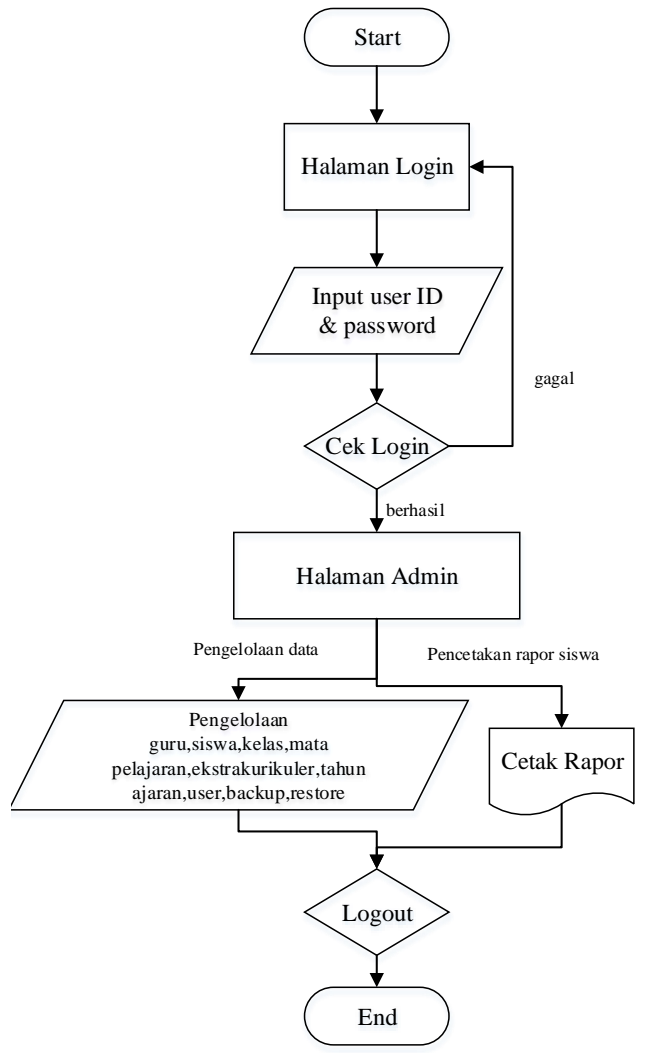

Gambar 6. Flowchart admin

Flowchart merupakan pembuatan bagan alir yang menunjukkan gambaran aliran (flow) di dalam sistem secara logika. Flowchart yang terjadi pada sistem informasi akademik yang dibuat seperti pada Gambar 4, Gambar 5 dan Gambar 6.

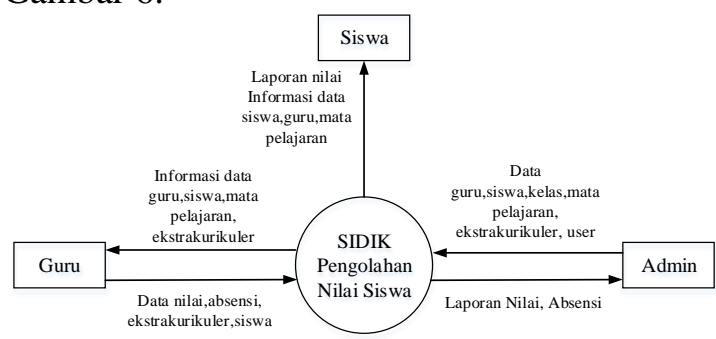

Gambar 7. DFD Level 0 SIDIK

Pada Gambar 7 menunjukkan tentang DFD Level 0 dari SIDIK (Sistem Informasi Akademik) yang dikembangkan. DFD Level 0 menjelaskan tentang gambaran sistem secara keseluruhan yaitu hubungan antara entitas (Admin, Guru dan Siswa) dengan sistem yang dikembangkan.

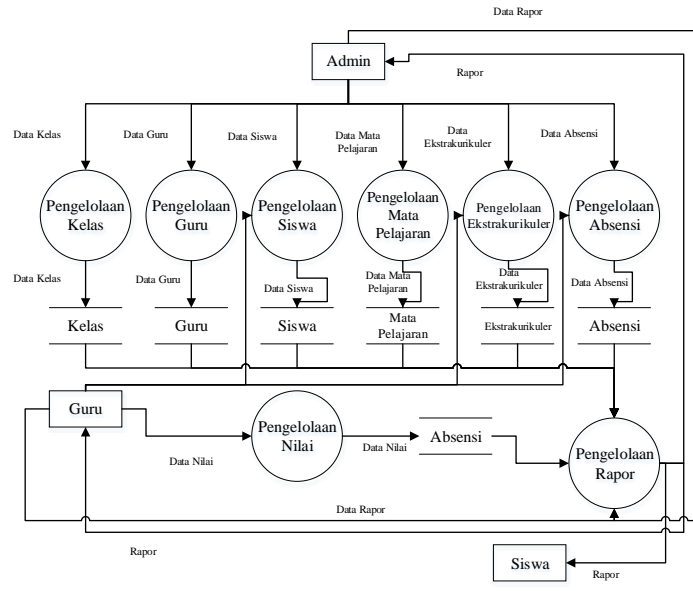

Gambar 8. DFD Level 1

Pada Gambar 8 menunjukkan tentang DFD Level 1 dari SIDIK (Sistem Informasi Akademik) yang dikembangkan. DFD Level 1 menjelaskan tentang data yang mengalir melewati proses - proses yang ada dalam sistem yang telah dibuat.Terdapat beberapa proses yang ada pada DFD Level 1 yaitu proses pengelolaan kelas, guru, siswa, mata pelajaran, ekstrakurikuler, absensi, nilai dan rapor.

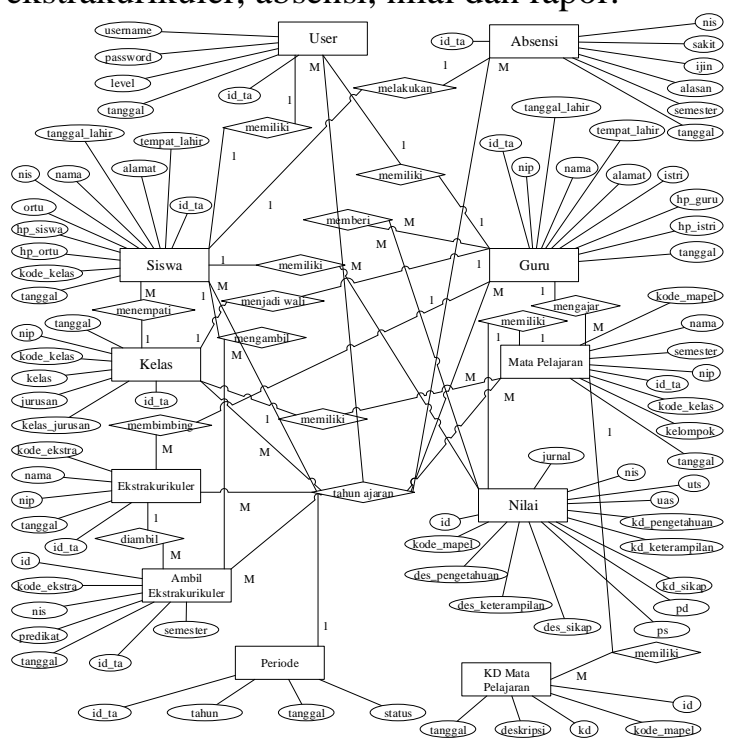

Gambar 9. Rancangan ERD

Pada Gambar 9 menunjukkan tentang rancangan ERD (Entity Relationship Diagram) yang dibuat pada sistem yang dikembangkan. ERD adalah hubungan antara tiap entitas, atribut tiap entitas dan relasi antar entitas. Kemudian setelah pembuatan rancangan ERD dilakukan, kemudian membuat rancangan desain tampilan sebagai pedoman untuk berlanjut pada tahap selanjutnya yaitu tahap construction.

Tahap Constrution 
Tahap construction adalah tahapan pada rancangan yang telah di buat sebelumnya, kemudian dibentuk menjadi suatu kode (program) yang siap untuk dioperasikan.

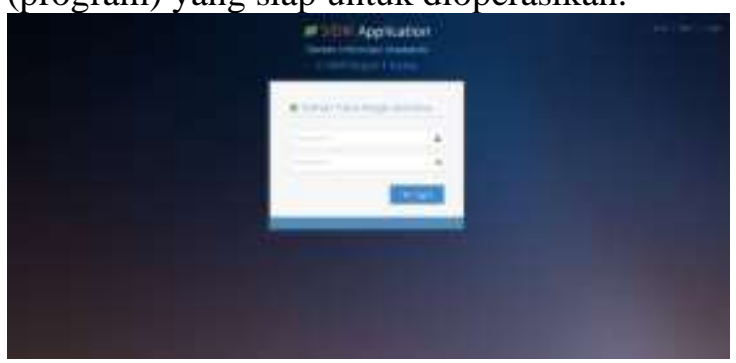

Gambar 10. Halaman Depan Sistem Informasi Akademik

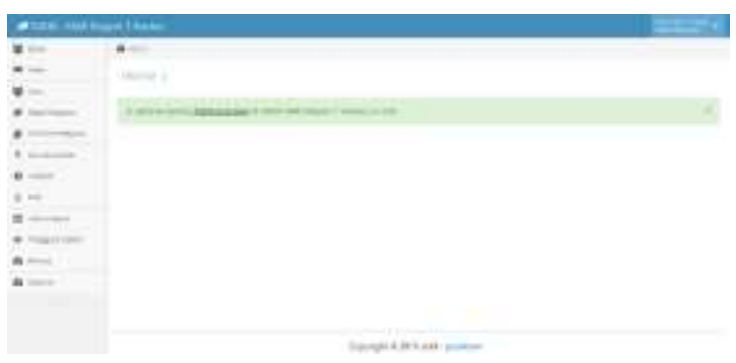

Gambar 11. Halaman Admin

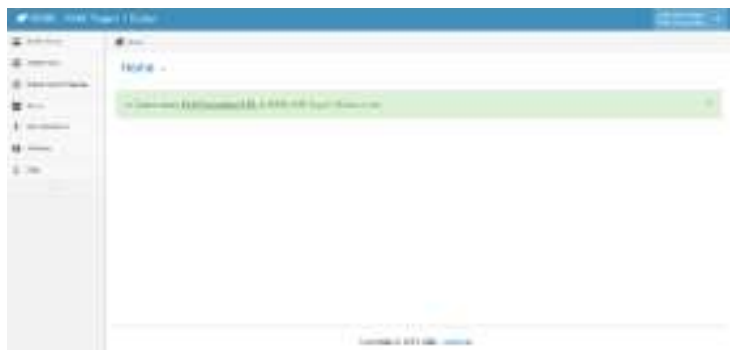

Gambar 12. Halaman Guru

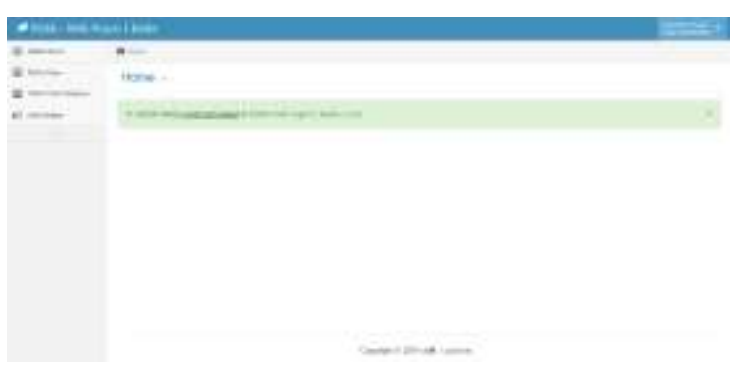

Gambar 13. Halaman Siswa

Hasil dari tahap construction menghasilkan antarmuka pengguna (user interface) dari Sistem Informasi Akademik Berbasis Web Sebagai Sistem Pengolahan Nilai Siswa seperti pada Gambar 10, Gambar 11, Gambar 12 dan Gambar 13.

Tahap Deployment

Tahap deployment adalah tahapan akhir dari pengembangan sistem yang telah selesai dibuat. Pengujian pada sistem dilakukan dengan memberikan kuesioner kepada 2 ahli sistem yaitu Bapak Rosihan Ari Yuana S.Si, M.Kom dan Bapak Puspanda Hatta S.Kom, M.Eng, 5 ahli substansi yaitu Bapak Dwi Maylain S.Kom, Bapak Bicharur Rohman S.Kom, Bapak Andry Fitrianto S.Kom, Bapak Alex Fahrudin S.Kom dan Bapak Muhammad Aulal Faqih serta 30 siswa kelas X Akuntansi 1 serta siswa kelas X AK 1 SMK Negeri 1 Kudus. Pengujian bertujuan untuk memastikan bahwa sistem yang telah dikembangkan sesuai dengan kebutuhan sehingga Sistem Informasi Akademik layak untuk digunakan.

Tabel 2. Penilaian Pengujian oleh Ahli Sistem Informasi

\begin{tabular}{clc}
\hline No. & \multicolumn{1}{c}{ Indikator } & Nilai \\
\hline & $\begin{array}{l}\text { Ketepatan pemilihan } \\
\text { perangkat lunak unis } \\
\text { pengembangan }\end{array}$ & $90 \%$ \\
\hline 2 & Kemudahan akses & $98 \%$ \\
\hline 3 & Proses dan aliran data & $88.3 \%$ \\
\hline 4 & Tampilan program & $94 \%$ \\
\hline 5 & Keberlanjutan program & $95 \%$ \\
\hline Rerata & $\mathbf{9 3 . 1 \%}$ \\
\hline
\end{tabular}

Setelah dilakukan pengujian oleh ahli sistem informasi memberikan saran untuk perbaikan dan pengembangan sistem informasi akademik sebagai berikut :

a) Entri nilai oleh guru dapat dilakukan via import excel.

b) Tampilan data nilai sesuai dengan mata pelajaran yang diampu oleh guru sehingga tidak memberatkan dalam pemrosesan loading data.

c) Menambahkan pemfilteran karakter terhadap data POST dan GET untuk mencegah peretasan ke MySQL.

Sistem Informasi Akademik telah diperbaiki sesuai dengan saran ahli sistem informasi.

Tabel 3. Penilaian Pengujian oleh Ahli Substansi

\begin{tabular}{clc}
\hline No. & \multicolumn{1}{c}{ Indikator } & Nilai \\
\hline 1 & Kesesuaian sistem & $83 \%$ \\
\hline 2 & $\begin{array}{l}\text { Kelengkapan data atau rekap } \\
\text { data yang dihasilkan }\end{array}$ & $87 \%$ \\
\hline 3 & Kestabilan program & $86 \%$ \\
\hline Rerata & $\mathbf{8 5 . 3 \%}$ \\
\hline \multicolumn{2}{l}{ Setelah dilakukan pengujian }
\end{tabular}

Setelah dilakukan pengujian oleh ahli substansi memberikan saran untuk perbaikan 
dan pengembangan sistem informasi akademik sebagai berikut :

a) Sistem login masih kurang sempurna

b) Redundansi data masih ada

c) Penambahan pada fasilitas cetak berdasarkan kelas

Sistem Informasi Akademik telah diperbaiki sesuai dengan saran ahli substansi.

Pengujian oleh siswa dilakukan dengan menggunakan metode hitung kuisioner SUS (System Usability Scale)(HHS, (2006) dan Sauro, J., (2011)).

Tabel 4. Penilaian Pengujian oleh Siswa

\begin{tabular}{|c|c|c|}
\hline No. & Kuesioner & Nilai \\
\hline 1 & $\begin{array}{lr}\text { Saya berpikir untuk } & \text { sering } \\
\text { menggunakan } & \text { sistem } \\
\text { informasi ini } & \\
\end{array}$ & 108 \\
\hline 2 & 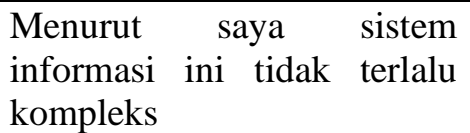 & 92 \\
\hline 3 & $\begin{array}{lcc}\text { Menurut } & \text { saya } & \text { sistem } \\
\text { informasi } & \text { ini } & \text { mudah } \\
\text { digunakan } & & \\
\end{array}$ & 106 \\
\hline 4 & 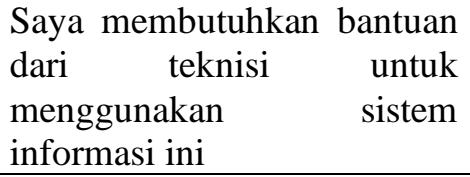 & 97 \\
\hline 5 & $\begin{array}{l}\text { Saya menemukan berbagai } \\
\text { fungsi dalam sistem } \\
\text { informasi ini berjalan dengan } \\
\text { baik }\end{array}$ & 107 \\
\hline 6 & $\begin{array}{l}\text { Saya berpikir terlalu banyak } \\
\text { inkonsistensi pada sistem } \\
\text { informasi ini }\end{array}$ & 90 \\
\hline 7 & $\begin{array}{l}\text { Menurut saya kebanyakan } \\
\text { orang akan dengan mudah } \\
\text { mempelajari penggunaan } \\
\text { sistem informasi ini }\end{array}$ & 107 \\
\hline 8 & $\begin{array}{lll}\text { Menurut saya } & \text { sistem } \\
\text { informasi ini sangat } & \text { rumit } \\
\text { digunakan } & & \\
\end{array}$ & 101 \\
\hline 9 & $\begin{array}{l}\text { Saya merasa sangat percaya } \\
\text { diri menggunakan sistem } \\
\text { informasi ini }\end{array}$ & 97 \\
\hline 10 & $\begin{array}{l}\text { Saya perlu banyak belajar } \\
\text { untuk dapat menggunakan } \\
\text { sistem informasi ini }\end{array}$ & 84 \\
\hline \multicolumn{2}{|c|}{ Jumlah } & 989 \\
\hline \multicolumn{2}{|c|}{$\begin{array}{ll}\text { Jumlah perhitungan } & \text { SUS } \\
\text { (Jumlah } \times 2,5) & \\
\end{array}$} & 2472,5 \\
\hline \multicolumn{2}{|c|}{$\begin{array}{l}\text { Rata - rata nilai SUS dalam } \\
\text { persentase }\end{array}$} & $82,4 \%$ \\
\hline
\end{tabular}

Dari hasil uji coba dengan menggunakan kuesioner oleh ahli sistem informasi, ahli substansi dan siswa terhadap beberapa indikator yang diuji menghasilkan rata - rata nilai masing - masing $93,1 \%, 85,3 \%$, dan $82,4 \%$. Hasil tersebut menunjukkan bahwa sistem informasi yang dikembangkan mendapatkan nilai diatas $81 \%$, sehingga dapat dikatakan bahwa Sistem Informasi Akademik Sebagai Sistem Pengolah Nilai Siswa di SMK Negeri 1 Kudus masuk dalam kategori sangat layak.

Kajian Produk Akhir

Setelah sistem informasi selesai dibuat, kemudian dilakukan tahap uji coba dan di revisi. Dari semua tahapan menghasilkan produk akhir yang layak untuk digunakan. Peneliti mendapatkan informasi tentang hasil dari produk akhir yang telah dikembangkan yaitu keunggulan dan kekurangan produk tersebut yaitu :

1. Keunggulan

a. Sistem yang dikembangkan berbasis $w e b$, sehingga mudah untuk diakses menggunakan browser.

b. Memudahkan guru dalam pengelolaan nilai.

c. Data tersimpan dalam basis data sehingga data dapat terpusat dan dapat dilakukan backup dan restore kapanpun.

d. Sistem Informasi Akademik yang dikembangkan dapat dipakai pada instansi lain yang memiliki alur pengelolaan nilai yang hampir sama.

2. Kekurangan

a. Belum adanya integrasi dengan portal sekolah yang dapat memberikan layanan yang terintegrasi.

b. Tidak ada notifikasi secara realtime kepada smartphone siswa ketika nilai sudah masuk ke dalam basis data Sistem Informasi Akademik.

c. Peningkatan keamanan pada website agar tidak dengan mudah dilakukan peretasan website oleh pihak yang tidak bertanggung jawab.

\section{Simpulan dan Saran \\ Simpulan}

1. Sistem Informasi Akademik Berbasis Web Sebagai Sistem Pengolahan Nilai Siswa Di SMK Negeri 1 Kudus dikembangkan 
melalui lima tahap. Tahap pertama yaitu Communication yang merupakan tahapan inisiasi sistem yang akan dikembangkan. Tahap kedua yaitu Planning yang merupakan tahapan analisis kebutuhan sistem. Tahap ketiga yaitu Modelling yang meliputi perancangan Usecase, perancangan Flowchart, perancangan DFD, perancangan ERD, perancangan basis data dan perancangan desain tampilan. Tahap keempat yaitu Construction yang merupakan tahapan implementasi pada sistem yang akan dikembangkan. Tahap kelima yaitu Deployment meliputi tahap uji coba yang terdiri dari uji coba ahli sistem, uji coba ahli substansi dan uji coba siswa.

2. Kelayakan dari sistem yang dikembangkan dilakukan pada tahap kelima. Dari hasil uji coba, Sistem Informasi Akademik Berbasis Web Sebagai Sistem Pengolahan Nilai mendapatkan penilaian sebesar $93,1 \%$ dari ahli sistem, $85,3 \%$ dari ahli substansi dan $82,4 \%$ dari siswa, sehingga dapat disimpulkan bahwa Sistem Informasi Akademik Berbasis Web yang dikembangkan sangat layak untuk digunakan sebagai sistem pengolahan nilai siswa.

\section{Saran}

1. Perlu peningkatan dalam segi keamanan website agar tidak mudah diretas oleh pihak yang tidak bertanggung jawab.

2. Perlu sosialisasi kepada guru dan siswa agar penggunaan sistem informasi akademik berjalan dengan lancar.

3. Perlu pengembangan sistem pada aplikasi versi mobile, sehingga dapat memberikan notifikasi secara realtime kepada para penggunanya dan memberikan kemudahan akses pada smartphone tanpa melalui browser.

\section{Daftar Pustaka}

Bharamagoudar, S.R, Geeta, R.B, Totad, S.G. (2013). Web Based Student Information Management System. IJARCCE.

Fadjar. 2002. Sistem Informasi Akademik. Yogyakarta: Andi Offset

Gurid Budi Wiyono, I. U. (2014). Pembangunan Sistem Informasi Akademik Pada Sekolah Menengah Pertama (SMP) Negeri III Tegalombo. Indonesian Journal on Networking and Security, 8 .

HHS. (2006). System Usability Scale. Diperoleh 27 April 2016 dari, https://www.usability.gov/how-to-andtools/methods/system-usabilityscale.html.

James OBrien, G. M. (2010). Management Information Systems. New York: McGraw-Hill.

Pressman, R. S. (2010). Software Engineering a Practitioner Approach, Seven Edition (Vol. 7). New York: McGraw-Hill.

Romas, MH. Fahd Al Aliem. (2015). Pengembangan Sistem Informasi Borang Akreditasi Berbasis Web Pada Program Studi Pendidikan Teknik Mesin JPTK FKIP UNS. Skripsi Tidak Dipublikasikan: UNS, Surakarta.

Sauro, J. (2011). Measuring Usability with the System Usability Scale (SUS). Diperoleh 27 April 2016 dari, http://www.measuringu.com/sus.php.

Sugiyono. (2014). Metode Penelitian Kuantitatif, Kualitatif dan $R \& D$. Bandung: Alfabeta.

Suharsimi, A. (2010). Prosedur Penelitian Suatu Pendekatan Praktik. Jakarta: Rineka Cipta. 